\title{
IMMEDIATE EFFECT OF INCENTIVE SPIROMETRY ON ARTERIAL BLOOD GASES ANALYSIS AFTER CORONARY BYPASS GRAFT SURGERY PATIENTS
}

\author{
Shagufta Khan ${ }^{1}$, Abhijeet Diwate ${ }^{2}$, Arijit Kumar Das ${ }^{3}$
}

${ }^{1}$ UG student, ${ }^{2}$ Professor 3 Professor, Department of Cardiorespiratory and vascular sciences, D.V.V.P.F's College of physiotherapy, Ahmed Nagar, Maharashtra, India.

\section{ABSTRACT}

Background: The patients who have done CABG are prone to pulmonary complications. Various physiotherapy management is present for prevention of lung complication. Literature shows lots of technique as treatment of choice, incentive spirometry is one of them. AIM: To asses immediate effect of incentive spirometry on arterial blood gas analysis in patient recently underwent coronary artery bypass surgery. Method: There was 30 patients. Blood was drawn from arterial line for pre-treatment ABG. Incentive spirometry was given 10 reps and 3 sets. Patient was prop up 30-40 degree. Romsons tri colour volume spirometry is used. Mouthpiece was placed in patient's mouth and made a good seal over the mouthpiece with lips. Exhaled through nose normally then breathe in slowly through mouth. Ball in the incentive spirometer will go up. The patient to hold or rise the ball as high as possible and hold it for 3 or 5 seconds the slowly exhale. This was done for 10 to 15 times. Blood was drawn from arterial line for post treatment ABG. Result: There was statistically extremely significant change in value of $\mathrm{PaO} 2$ (112.54 \pm 39.46 vs133.01 $\pm 42.13) \mathrm{p}$ value $<0.0001, \mathrm{PaCO} 2(38.75 \pm 4.2$ vs $36.9 \pm 3.7) \mathrm{p}$ value 0.0003 and $\mathrm{SaO} 2(96.8 \pm 1.84$ vs $98.93 \pm 1.11) \mathrm{p}$ value $<0.0001$ Conclusion: This study shows that there is immediate effect of Incentive Spirometry on ABG analysis in CABG surgery patient by significant improvement of $\mathrm{PaO} 2$ and $\mathrm{SaO} 2$ and decrease in $\mathrm{PaCO} 2$

KEYWORDS: Incentive spirometry; Arterial blood gas analysis; coronary artery bypass graft surgery.

\section{INTRODUCTION}

Coronary artery bypass surgery is one of the widely used treatments as every year more than 1 million coronary artery bypass surgery procedures are performed around the world [1]. The patients who have coronary artery bypass graft (CABG) are prone to pulmonary complications [2]. Pulmonary complication is highly common after the coronary artery bypass surgery and the incidence is between $30 \%$ and $60 \%$. These complications are the most significant contributor to morbidity, mortality, and expenses associated with the hospitalization. Success rate of CABG depends upon pulmonary complication in post-operative period. Advancement of pulmonary complication is linked with impaired oxygenation and inconsistencies in gas exchange. As the investigations have shown, arterial hypoxemia following CABG is $100 \%$ [3].

The postoperative pulmonary complications present high rates of morbidity and mortality, increased hospital costs, and prolonged hospital stay after coronary artery bypass surgery; it is obvious that the need for

\begin{tabular}{|l|l|}
\hline & DOI: $10.31878 /$ ijcbr.2018.44.05 \\
\hline
\end{tabular}

the breathing exercises is important

Immediate after surgery there are complication present due to anesthesia such as mucociliary movement will be reduced because of ciliary paralysis which lead to retention of secretion. Due to pain on suture site there will be reduction in chest mobility and expansion. Diaphragm movement is reduced because of incision, pain and generalised weakness leading to atelectasis. As the lung capacity is reduced, and there is high chance of developing atelectasis. Lack of chest mobility and reduced air entry leads to hypoxia in body [4].

Because there are no planned breathing exercises, on one hand, in our open heart surgery intensive care unit (ICU) nowadays, and on the other hand, there are various results and controversies among related studies in this context, researchers decided to examine the effect of incentive spirometry on the gas exchange and oxygenation after coronary artery bypass surgery. To evaluate the impact of this method on oxygenation and gas exchange, the arterial blood gases can be measured because the measurement of arterial blood gases is one of the most reliable indices for determination of gas exchange and oxygenation. In the postoperative cardiac surgery period, the hemodynamic monitoring and maintaining hemodynamic stability are controlled by inserted arterial line; as a result, sampling for arterial blood gas analysis is really convenient.

Correspondence: Shagufta Khan, D.V.V.P.F's College of Physiotherapy, Ahmed Nagar.

E-mail: kh.shagufta@gmail.com

International Journal of Clinical and Biomedical Research. (C) 2018 Sumathi Publications.

This is an Open Access article which permits unrestricted non-commercial use, provided the original work is properly cited. 
Various physiotherapy management is present for prevention of lung complication. Literature shows lots of technique as treatment of choice, incentive spirometry is one of them. Principle of incentive spirometry is sustained maximal inspiration and is component of bronchial hygiene therapy, it helps to increase trans pulmonary pressure and inspiratory volumes, improve inspiratory muscle performance and re-establish or stimulate the normal pattern of pulmonary hyperinflation [1].

Post-operative spirometry is important component to prevent pulmonary complication. So spirometry is given 10 reps once or twice[2] article shows there is direct effect of spirometry on arterial blood but how it effect immediately is not yet very much clear. Therefore this study is mainly to find out only immediate effect of spirometry.

\section{MATERIALS AND METHODS}

Study design: Intervention Study.

Ethics approval: Ethical consent from institutional ethical committee was gained. Subject fulfilling inclusive criteria was selected for the study, procedure was explained to participants and written consent was taken.

Study location: D.V.V.P.F's Hospital, Ahmed Nagar.

Study duration: 6 months.

Inclusion criteria: Patient underwent non-emergency coronary artery bypass graft surgery, participate patient should not have mental or neuromuscular disorder, not suffering any renal disorder and mechanical ventilation should be less than 24 hour.

Exclusion criteria: Patient diagnosed with pulmonary disease, circulatory disorder and subject uncooperative and unwilling to participate.

\section{Sample size: 30 .}

\section{METHODOLOGY}

Blood was drawn from arterial line for pre-treatment ABG. Incentive spirometry was given 10 reps and 3 sets. Patient was prop up 30-40 degree. Romsons tri colour volume spirometry is used. Insert the mouthpiece in your mouth. Make sure to make a good seal over the mouthpiece with lips. Exhale through nose normally then breathe in slowly through mouth. Ball in the incentive spirometer will go up ask the patient to hold or rise the ball as high as possible and hold it for 3 or 5 seconds the slowly exhale. This was done for 10 to 15 times [2]. Blood was drawn from arterial line for post treatment $A B G$. Blood parameter taken into consideration was $\mathrm{PaO}_{2}, \mathrm{PaCO}_{2}$ and $\mathrm{SaO}_{2}$.

Statistical analysis: Statistical analysis: Data was analysed by instat version 3 by paired t test method. Paired $t$ test is used to compare two population means where you have two samples in which observation in one sample can be compare to observation in other group.

\section{RESULT}

There was statistically extremely significant change in value of $\mathrm{PaO}_{2}$ between pre and post (112.54 \pm 39.46 vs133.01 \pm 42.13$)$ p value $<0.0001, \mathrm{PaCO}_{2}(38.75 \pm 4.2$ vs $36.9 \pm 3.7) \mathrm{p}$ value 0.0003 and $\mathrm{SaO}_{2}(96.8 \pm 1.84$ vs 98.93 \pm 1.11 ) $\mathrm{p}$ value $<0.0001$ (Figure 1 ).

This shows that after Incentive spirometry the $\mathrm{PaO}_{2}$ and $\mathrm{SaO}_{2}$ value was increased significantly whereas $\mathrm{PaCO}_{2}$ value was decreased.

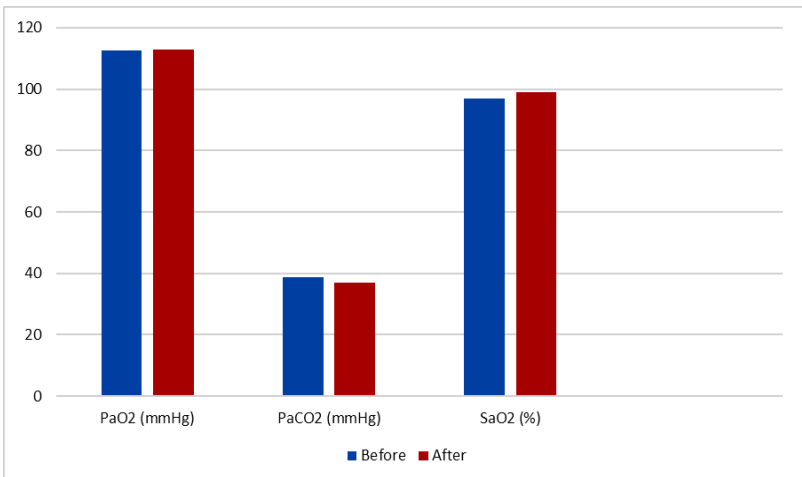

Figure 1. Changes between pre and post $\mathrm{PaO}_{2}$ values

\section{DISCUSSION}

Coronary artery bypass surgery is one of the widely used treatments as every year more than 1 million coronary artery bypass surgery procedures are performed around the world. The patients who have coronary artery bypass graft (CABG) are prone to pulmonary complications[1] After CABG, the respiratory exercises consist of deep breathing exercise, IS, intermittent positive pressure, and early mobilization, which are practiced with the aim of improving pulmonary function. [3].

The postoperative pulmonary complications present high rates of morbidity and mortality, increased hospital costs, and prolonged hospital stay after coronary artery bypass surgery; it is obvious that the need for the breathing exercises is important

General anesthesia and mechanical ventilation impair pulmonary function, even in normal individuals, and result in decreased oxygenation in the postanesthesia period. They also cause a reduction in functional residual capacity of up to $50 \%$ of the preanesthesia value. It has been shown that pulmonary atelectasis is a common finding in anesthetized individuals [4].

Yazdannik et al,has done study on The effect of incentive spirometry on arterial blood gases after coronary artery bypass surgery (CABG) Result shows difference between the intervention and control groups in the mean amount of arterial blood oxygen, arterial blood 
carbon dioxide and oxygen saturation Conclusion of this article is that using incentive spirometry is significantly effective in the improvement of blood arterial gas parameters.[4]

Incentive spirometry is one of the important part in cardiac rehabilitation. This study shows changes in 3 parameter $\mathrm{PaO} 2, \mathrm{PaCO} 2$ and $\mathrm{SaO} 2$. Increase in $\mathrm{PaO} 2$ helps to rapidly bind Oxygen molecule to Haemoglobin molecule as the binding speed rises oxygen saturation percentage rises rapidly in oxygen dissociation curve. [5] Increase in $\mathrm{SaO} 2$ helps to transfer oxygen molecule from blood through capillaries to the tissue. More Oxygen to the tissue helps in healing faster. This also helps in early mobilization and early release from hospital.

A systematic review was conducted by Agostini et al. and Sally Singh about "Incentive spirometry following thoracic surgery: what should we be doing?"- Physiological evidence suggests that incentive spirometry may be appropriate for lung re-expansion following major thoracic surgery [6] so it support the result of this study.

Brage stated that "Improvement in blood oxygenation by respiratory exercises is temporary and is reversible after a short time." So, for improvement in oxygenation repetitive exercises are needed [7].

Afrasiabi et al. measured the arterial blood gases only 6 $\mathrm{h}$ after extubation; in our study also, there were no significant differences in the mean arterial blood gas parameters between the two groups on the second postoperative day, but there was a significant difference in the mean arterial blood gas parameters between the groups on the third postoperative day.[8]

Above study support the result of this study that there is immediate effect of Incentive spirometry on Arterial blood gas analysis ( $\mathrm{PaO} 2, \mathrm{PaCO} 2$ and $\mathrm{SaO} 2)$ after Coronary Artery Bypass Graft Surgery patient.

\section{CONCLUSION}

This study shows that there is immediate effect of Incentive Spirometry on ABG analysis in CABG surgery patient by significant improvement of $\mathrm{PaO} 2$ and $\mathrm{SaO} 2$ and decrease in $\mathrm{PaCO} 2$ resulting less hospital stay and early mobilization.

Limitation: Sample size was small, age Group was not specific and Smoker and Non-smokers were not differentiated.

Acknowledgement: Firstly, I would like to express my sincere gratitude to my advisor Dr. Abhijeet Diwate HOD and Prof. of Cardiovascular and Pulmonary science and Dr. Arijit Kumar Das Prof. of Cardiovascular and Pulmonary science for the continuous support of my study and related research, for their patience, motivation, and immense knowledge. Their guidance helped me in all the time of research and writing of this paper. I could not have imagined having a better advisor and mentor for my study.

\section{REFERENCES}

1) AARC clinical practice guideline available at https:// www.aarc.org/wp-content/ uploads/2014/08/01.99.99.pdf accessed on 10.3.2018

2) AARC Clinical Practice Guideline, Respir Care. 1991;36(12):1402-1405

3) Keenan TD, Abu?Omar Y, Taggart DP. Bypassing the pump: Changing practices in coronary artery surgery. Chest. 2005;128:363]9.

4) Marcin Karcz, MD MSc and Peter J Papadakos, M, Respiratory complications in the postanesthesia care unit: A review of pathophysiological mechanisms. CJRT winter 2013, 21-29

5) GopalaKrishnaAlaparthi et al., Comparison of Diaphragmatic Breathing Exercise, Volume and Flow Incentive Spirometry, on Diaphragm Excursion and Pulmonary Function in Patients Undergoing Laparoscopic Surgery: A Randomized Controlled Trial 2016. 1-12. www.hindawipublisingcorporation.in

6) Paula Agostini and Sally Singh, Incentive spirometry following thoracic surgery: what should we be doing? , Physiotherapy Volume 95, Issue 2, June 2009, Pages 76-82

7) Agostini $P$, Singh S. incentive spirometry following thoracic surgery: what should we be doing? Physiotherapy 2009; 95:76-82

8) Afrasiabi A, Hasanzadeh S, Negargar S, Ghafari MR, Ansarin K. The effect of incentive spirometry on pulmonary volumes and arterial blood gases after coronary artery bypass surgery. J Kermanshah Univ Med Sci. 2007;10:1. 